\title{
Relationship Between Soilborne and Seedborne Inoculum Density and the Incidence of Dwarf Bunt of Wheat
}

\author{
Blair J. Goates, United States Department of Agriculture-Agricultural Research Service (USDA-ARS), National \\ Small Grains Germplasm Research Facility, P.O. Box 307, Aberdeen, ID 83210; and Gary L. Peterson, USDA- \\ ARS, Foreign Disease Weed Science Research Unit, 1301 Ditto Ave., Fort Detrick, MD 21702-5023
}

\begin{abstract}
Goates, B. J., and Peterson, G. L. 1999. Relationship between soilborne and seedborne inoculum density and the incidence of dwarf bunt of wheat. Plant Dis. 83:819-824.

The incidence of dwarf bunt of wheat as a function of inoculum density was studied in a susceptible and a partially resistant cultivar at three disease-conducive locations for three seasons. Prior to seeding, plots were fumigated with methyl bromide to eliminate residual inoculum. Each cultivar was seeded into two 1.2-m rows in four replicates. The soil surface was inoculated with $0,16 \times 10^{2}, 16 \times 10^{3}, 16 \times 10^{4}, 16 \times 10^{5}$, and $16 \times 10^{6}$ teliospores of Tilletia controversa per row, or seed was inoculated with $0,2 \times 10^{2}, 2 \times 10^{3}, 2 \times 10^{4}, 2 \times 10^{5}$, and $2 \times 10^{6}$ teliospores per gram. To determine maximum possible infection, two $3.1-\mathrm{m}$ rows of each cultivar were soilsurface inoculated at $10 \times$ the highest treatment rate. In the soil-inoculated plots, a minimum of $16 \times 10^{3}$ teliospores/row was needed to cause trace amounts of disease ( $0.6 \%$ maximum), even when the positive indicator treatment had up to $88 \%$ incidence. Only trace amounts or no disease occurred below the $16 \times 10^{5}$ rate. In the seed-inoculated plots, infection was rare and occurred only at inoculation rates of $2 \times 10^{5}$ teliospores/g or higher; the highest incidence was $0.4 \%$.
\end{abstract}

Additional keywords: epidemiology, smut

Dwarf bunt is a smut disease of winter wheat caused by the fungus Tilletia controversa Kühn in Rabenh. Infection occurs during the winter (17), when soilborne teliospores near the soil surface germinate and produce hyphae that penetrate seedlings after emergence, and become established in the apical meristem of tiller initials (3). Hyphae persist in the meristem during plant development and eventually enter the nascent caryopsis, where the fungus proliferates and sporulates forming teliospores in endosperm tissue. Typically, the entire grain is transformed into a generally spherical sorus termed a "bunt ball" that consists of a dark-colored mass of teliospores enveloped within a thin, papery remnant of the pericarp. Sori rupture during harvest or after becoming

Corresponding author: Blair J. Goates

E-mail: bgoates@uidaho.edu

Product names are necessary to report factually on available data; however, the USDA neither guarantees nor warrants the standard of the product, and the use of the name by USDA implies no approval of the product to the exclusion of others that may also be suitable.

Accepted for publication 14 May 1999.

Publication no. D-1999-0623-01R

This article is in the public domain and not copyrightable. It may be freely reprinted with customary crediting of the source. The American Phytopathological Society, 1999. saturated with water, releasing teliospores which contaminate the soil. Infected tillers are typically shorter than healthy tillers.

In the United States and world wide, dwarf bunt is restricted to areas that commonly have persistent snow cover and relatively warm temperatures over the winter (21). Dwarf bunt has the greatest potential to develop when deep, persistent snow occurs before the soil becomes frozen, which provides a long period of stable, cool, humid conditions that are optimal for teliospore germination and infection. The disease has not been recorded in areas with very cold winter climates, such as the Northern Great Plains of the United States and the Southern Canadian Prairies. Soils in these areas typically freeze during late fall to early winter, and it is believed that the soil temperatures over the winter are too low to support proper conditions for development of dwarf bunt, even though snow cover may last for an adequate period of time (D. Gaudet, personal communication). Low amounts of dwarf bunt have been observed or induced in the absence of snow cover when high levels of soil inoculum coincide with a long period of cool, cloudy, humid weather (25; B. J. Goates, unpublished). However, under natural conditions in commercial fields, dwarf bunt is an economic problem only where sufficient inoculum from a previously infected crop is present in conjunction with persistent snow cover.
Historically, dwarf bunt has caused significant yield and quality losses (11), but the disease is currently under excellent control in the United States through the use of resistant cultivars $(7,9,18)$ and use of the highly effective fungicide seed treatment chemical, difenoconazole $(6,14,19)$. Currently, the disease is of concern most often because of phytosanitary issues that influence international markets (15). In particular, the People's Republic of China (PRC), one of the major importers of U.S. wheat, has a quarantine against $T$. controversa. The PRC restricts the import of grain from the northwestern United States, where wheat is commonly contaminated with teliospores of the fungus in at least trace amounts that can be easily detected with non-sophisticated techniques (10).

Previously, dwarf bunt was thought to be caused by a race or biotype of the common bunt fungus T. tritici (Bjerk.) Winter (24). Part of the reason for the eventual distinction of $T$. controversa as a separate species was that common bunt is easily induced with seedborne teliospores, whereas dwarf bunt is not $(13,23)$. In dwarf bunt epidemiology, seedborne inoculum is inconsequential to the development of disease in the resulting crop, but limited amounts of disease have been induced with very high levels of seedborne inoculum (10). The important consequence of planting teliospore-infested seed is the contamination of soils with long-lived teliospores that could effect future crops. Teliospores in soil under field conditions have been shown to survive in at least low levels for 10 years (22).

This study was conducted to determine the relationship between levels of teliospore inoculum and disease incidence of a susceptible and a partially resistant cultivar in varying environments. This information would allow better assessment of the risk of introducing dwarf bunt into new areas via teliospore-contaminated grain; in particular, to address international phytosanitary concerns (4). Teliospore contamination on seed or grain for domestic use in the United States is of no regulatory concern because dwarf bunt has apparently attained its ecological boundary. The primary objective of the study was to determine the level of teliospore inoculum required to cause infection in diseaseconducive field environments when inoculum is placed on the soil surface. A 
secondary objective was to assess disease caused by seedborne teliospores in diseaseconducive fields that are free of viable teliospores. A previous study (10), conducted in numerous locations, addressed the seedborne aspect of the epidemiology of dwarf bunt in fields that were usually naturally contaminated with teliospores, but statistical methods were mostly relied upon to differentiate the effects of teliospores applied to seed from natural infection in non-inoculated controls.

\section{MATERIALS AND METHODS}

Field locations. Experiments were conducted during the 1993 to 1994,1994 to 1995 , and 1995 to 1996 seasons at three locations that commonly have diseaseconducive weather. The locations were a rain-fed irrigated farm at the Montana State University Research Center near Kalispell, Montana; an irrigated farm operated by the Utah State University Experiment Station at Logan, Utah; and a dryland farm located at the base of a mountain range just east of Logan called the Green Canyon Nursery Site, where dwarf bunt screening nurseries have been conducted for many years.

Fumigation. At 4 to 10 days before seeding, plots were fumigated with methyl bromide at a rate of $0.91 \mathrm{~kg} / 9.3 \mathrm{~m}^{2}$ to kill teliospores naturally present in the soil. Each location had two adjacent plots $(8.8 \times$ $26.8 \mathrm{~m}$ ) that were each covered with a single sheet of 6-ml thick plastic. The plastic tarps were put in place 1 to 7 days prior to the fumigation. One plot was used for the seedborne inoculum study and the other for the soilborne inoculum study. Methyl bromide was injected beneath the plastic tarp at a minimum of 12 places around the perimeter of each plot. The tarp was removed immediately prior to seeding. Because fumigation under high humidity favors teliospore mortality (20), fields were irrigated, if necessary, prior to placing the tarp at Kalispell and Logan to insure high soil moisture, but irrigation was not available at Green Canyon.

The efficacy of the fumigation on loose teliospores and on teliospores contained within intact sori (bunt balls) was tested at each field site, with samples placed at 0,5 , 10 , and $20 \mathrm{~cm}$ beneath the soil surface at three locations under the tarp, and one location outside the plot as a control. The samples were prepared by mixing teliospores or intact sori with soil from the respective sites. Teliospore-contaminated soil $(5 \mathrm{~g})$, and seven intact sori in $5 \mathrm{~g}$ of soil, were placed in bags ( 4 by $7 \mathrm{~cm}$ ) made of nylon mesh with a 20- $\mu \mathrm{m}$ pore size (Spectrum Medical Industries, Inc., Houston, TX). After fumigation, teliospores in soil were recovered using a modified method of Datnoff and coworkers (2) which included mixing the $5 \mathrm{~g}$ of soil and $20 \mathrm{ml}$ of $50 \%$ aqueous glycerol with a magnetic stir bar for $5 \mathrm{~min}$ in a 100-ml beaker. After settling for $10 \mathrm{~min}$, the supernatant glycerol solution contained suspended teliospores and fine soil particles. The teliospore suspension was aspirated from the beaker and centrifuged to separate the teliospores, which were then rinsed by resuspending them in water twice for 5 min. Sori were removed from the soil in bags, then crushed in water to suspend the teliospores. The suspensions were filtered through cheese cloth and then resuspended in $10 \mathrm{ml}$ of water. The suspensions were left at ambient room temperature for $24 \mathrm{~h}$ to allow germination or hydration of contaminating fungi present in the soil, making them easier to kill in the following treatment. Standard methods were used to surface sterilize the teliospores for $1 \mathrm{~min}$ in $0.25 \% \mathrm{NaOCl}$ and plate them on $2 \%$ soil extract agar in two 9-cm plastic Petri dishes per sample (8). Teliospores were incubated at $5^{\circ} \mathrm{C}$ with $12 \mathrm{~h}$ of daily illumination for up to 160 days and were examined periodically for germinating teliospores. An estimated minimum of 40,000 spores/replicate at each depth and each field site was examined.

Field plots. The experiments were conducted in separate seed-inoculated and soil-inoculated plots as previously described. Seed was planted approximately 2 $\mathrm{cm}$ deep by hand during late September to early October. Planting at this time typically produces seedlings in the most susceptible 1- to 3-leaf stage as they enter dormancy in early winter (12). Furrows were opened with a hand plow and closed with a garden rake after placing seed from individual packets into the furrows. Each inoculum level was tested in four-replicate four-row plots arranged in randomized blocks. Each replicate four-row plot contained two $1.2-\mathrm{m}$ rows of the highly susceptible cultivar Cheyenne and two 1.2-m rows of the moderately susceptible cultivar Meridian, seeded at a rate of $4 \mathrm{~g}$ of seed/row. The cultivar Cheyenne is a hard red wheat typically used as a susceptible check in screening nurseries and fungicide efficacy tests, whereas cultivar Meridian is a moderately susceptible hard red wheat developed for irrigated areas where dwarf bunt is not a problem. To assure that no viable teliospores were present before the treatments were applied, all seed was pretreated with $1.6 \%$ aqueous $\mathrm{NaOCl}$ for 10 min, then rinsed and air dried. The four-row test plots were placed a minimum of $2.4 \mathrm{~m}$ inside the edge of the fumigated area and were surrounded with border rows of cultivar Cheyenne planted within the fumigated area. To avoid contaminating plots with nonfumigated soil on shoes and tools during planting and inoculation, movement in and out of the plots was minimized and, in 1994 to 1995 and 1995 to 1996 , when work outside the plots was required, as much work as possible was conducted on the fumigated surface of the plastic tarps after they were removed from the plots.
Inoculation. Teliospores used for inoculum at Kalispell and Logan originated from naturally occurring diseased spikes collected near the experimental sites. The inoculum for Green Canyon consisted of a composite of pathogenic races and isolates from throughout the western United States that is used for dwarf bunt screening nurseries at the site. The approximate number of teliospores per unit of weight was determined by diluting $0.100 \mathrm{~g}$ of teliospores in water until a reasonable number of teliospores could be counted with an improved Neubauer corpuscle counting chamber (Hausser Scientific, Blue Bell, PA). The mean of 10 counts was used to determine that there are approximately $4 \times 10^{8}$ teliospores/g.

To prepare the teliospore inoculum, sori from 20 spikes were crushed and the teliospores were sifted through a 100- $\mu \mathrm{m}$ screen. For the seed-inoculated plots, 1.00 $\mathrm{g}$ of teliospores was suspended in water, diluted to the proper concentration, and then $5.0 \mathrm{ml}$ of suspension was sprayed onto $100 \mathrm{~g}$ of seed placed in a single layer in a siliconized Pyrex baking dish (20 by 20 by $5 \mathrm{~cm}$; Corning, New York) at the rate of 2 $\times 10^{2}, 2 \times 10^{3}, 2 \times 10^{4}, 2 \times 10^{5}$, and $2 \times$ $10^{6}$ teliospores/g of seed. Based on separate analyses, about $10 \%$ of the inoculum remained on the dish. Seed was air dried for $24 \mathrm{~h}$, then placed into individual seed packets for each row. For the soil-inoculated plots, a suspension of teliospores was diluted to the proper concentration in 200 $\mathrm{ml}$ of water. A 3.8-liter garden sprayer was used to spray the $200 \mathrm{ml}$ onto the soil surface as evenly as possible in a $15-\mathrm{cm}$ band over the four rows $(50 \mathrm{ml} / \mathrm{row})$ of each four-row plot at the rate of $16 \times 10^{2}, 16 \times$ $10^{3}, 16 \times 10^{4}, 16 \times 10^{5}$, and $16 \times 10^{6}$ teliospores/row. The teliospores were applied within $24 \mathrm{~h}$ after planting. The seed and soil inoculation tests each contained four non-inoculated control plots. Prior to applying teliospores to the soil, a 0.6-m-high, $1.8 \times 1.2 \mathrm{~m}$ fence made of $0.96-\mathrm{cm}$-thick plywood and painted with white latex paint was placed around each four-row plot to prevent inoculum movement between plots during the fall and winter. The bottom of the fences was buried about $5 \mathrm{~cm}$ into the soil. The fences were removed in early April. Fences were not used in the seedinoculated plots. To determine the maximum possible infection in a given environment, two 3.1-m rows of cultivars Cheyenne and Meridian were planted near the test plots and were soil-inoculated as described at a rate at least $10 \times$ the highest test rate. Previous experience has shown that inoculation rates higher than this do not significantly increase disease (B. J. Goates, unpublished). These plots were included only in 1994 to 1995 and 1995 to 1996 and are reported in the results as the positive indicator. The positive indicator plot at Logan in 1995 to 1996 was accidentally destroyed during routine culti- 
vation. When plants were mature, the percent infected spikes in the two rows of each experimental unit was determined by examining individual spikes. Means and standard deviations were calculated from the four replicates of each variety, inoculum concentration, location, and year.

\section{RESULTS}

In general, plant stands were excellent in all plots in all years, and plants were at the most susceptible 1- to 3-leaf growth stage going into winter dormancy. The nurseries were in excellent condition in the spring, with the exception of slight damage from snow mold fungi at all locations in most years. The plots generally had excellent stands at maturity. In all years, at least one location showed high disease pressure evidenced by near maximum disease expression in the positive indicator plots and by the reaction of test plots. The fence that surrounded each soil-inoculated plot created a micro-climate that was warmer on the north side, which influenced plant emergence and growth. Plant rows were always oriented in a north-to-south direction, so the micro-climate influenced rows equally. Although plants at the north end of the rows were slightly further advanced during late fall and early spring, there was no noticeable difference in the incidence of disease at either end of the rows.

Fumigation with methyl bromide killed over $99.99 \%$ of teliospores (Table 1), enabling the introduction of known quantities of teliospores. In the teliospore viability assay, contaminating organisms did not grow in the Petri dishes prepared from the fumigated areas, and contamination in dishes from the control areas was absent or minimal and did not appear to influence teliospore germination. After the plastic tarps were put in place for the fumigation, water condensation appeared and remained on the underside of the tarps at Logan and Kalispell, indicating high humidity. After placing tarps at Green Canyon, water condensation on the underside of the plastic was either not present or just barely detectable in the corners of the tarp. During all years at Green Canyon, the soil was quite dry and moisture was not visibly apparent in the soil at less than $20 \mathrm{~cm}$ below the surface. Actual soil moisture was not determined.

In two cases, the fumigation apparently partially failed in a portion of the plots, evidenced by a small area approximately 2 $\mathrm{m}$ square where an estimated 7 to $11 \%$ disease incidence occurred in the non-inoculated cultivar Cheyenne border rows located directly adjacent to the test plots. This occurred adjacent to one replicated block of the seed-inoculated plots at Logan during 1995 to 1996, and adjacent to one block of the soil-inoculated plots at Green Canyon in 1995 to 1996 . Where the contamination occurred, it often appeared to influence a portion of the test plots, so data from the entire replicate block located adjacent to the area was excluded. Thus, final data for these two plots are based on three replicates rather than four. Failure of the fumigation did not appear to be a problem elsewhere.

At Green Canyon, the plots were located on a slope and, in 1994 to 1995 and 1995 to 1996 , heavy rains caused teliosporeinfested soil from the surrounding field to wash into the unfenced seed-inoculated plots as evidenced by soil erosion and infection in cultivar Cheyenne border rows. Also, infection occurred within the test plots where individual replicates of noninoculated cultivar Cheyenne had from 0 to $13 \%$ infection in 1995 and from 0.2 to $3.2 \%$ infection in 1996. Therefore, data from these plots were excluded from the results. At Green Canyon in 1994 to 1995 , two 24-m rows of cultivar Cheyenne planted in naturally infested soil near the experimental plots had approximately $80 \%$ infected spikes-demonstrating the highly contaminated nature of the soil and the disease-conducive conditions. The seed-inoculated plot was always placed uphill from the soil-inoculated plot at Green Canyon, which helped to prevent washing of contaminated soil into the soilinoculated plot. The fields at Kalispell and Logan were level, and movement of soil into these plots was minimal.

Border rows of cultivar Cheyenne adjacent to the outside edge of the fumigated areas were commonly diseased in at least trace amounts at all locations. In general, other than the problems at Green Canyon mentioned above, infection from outside contamination was confined to the rows close to the edge of the fumigated area and did not appear to interfere with the test plot results. However, it is possible that some of the infection within the test plots could have resulted from such contamination.

Disease incidence varied greatly among the locations and years (Tables 2 and 3). Overall, the Green Canyon plots produced the best conditions for infection and Kalispell the least. The Green Canyon site is highest in elevation and is situated on a northerly facing slope, where snow tends to collect earlier and remain longer than at the other locations. Disease in the cultivar Cheyenne positive indicator plots was theoretically the maximum amount of disease that could be produced in a given environment. Over the years, based on the reaction of the positive indicator plots, the relative disease pressure resulting from the environment appeared moderate to high at Green Canyon, low to moderate at Kalispell, and low to high at Logan. Although the 1995 to 1996 positive indicator plot at Logan was accidentally destroyed, the relatively high infection in the experimental plots indicated strong disease pressure. Similarly, the positive indicator plots were not planted in 1993 to 1994, but the infection potential of the

Table 1. Effects of fumigation with methyl bromide at $0.91 \mathrm{~kg} / 9.3 \mathrm{~m}^{2}$ on the viability of Tilletia controversa teliospores contained in bunt balls or existing free in the soil when placed at various levels in soil

\begin{tabular}{|c|c|c|c|c|c|c|}
\hline \multirow[b]{2}{*}{ Teliospores, depth (cm) } & \multicolumn{3}{|c|}{ Number of teliospores germinated ${ }^{a}$} & \multicolumn{3}{|c|}{ Germination $(\%)^{\mathbf{b}}$} \\
\hline & Green Canyon & Logan & Kalispell & Green Canyon & Logan & Kalispell \\
\hline \multicolumn{7}{|l|}{ Free spores } \\
\hline 0 & 12 & 0 & 3 & $\ldots$ & $\ldots$ & $\ldots$ \\
\hline 5 & 9 & 1 & 4 & $\ldots$ & $\ldots$ & $\ldots$ \\
\hline 10 & 1 & 9 & 0 & $\ldots$ & $\ldots$ & $\ldots$ \\
\hline 20 & 8 & 2 & 0 & $\ldots$ & $\ldots$ & $\ldots$ \\
\hline \multicolumn{7}{|l|}{ Non-fumigated } \\
\hline All & $\ldots$ & $\ldots$ & $\ldots$ & $89 \pm 2.2$ & $91 \pm 3.7$ & $93 \pm 3.4$ \\
\hline \multicolumn{7}{|l|}{ Bunt balls } \\
\hline 0 & 0 & 0 & 1 & $\ldots$ & $\ldots$ & $\ldots$ \\
\hline 5 & 1 & 0 & 0 & $\ldots$ & $\ldots$ & $\ldots$ \\
\hline 10 & 0 & 0 & 0 & $\ldots$ & $\ldots$ & $\ldots$ \\
\hline 20 & 1 & 0 & 0 & $\ldots$ & $\ldots$ & $\ldots$ \\
\hline \multicolumn{7}{|l|}{ Non-fumigated } \\
\hline All & $\ldots$ & $\ldots$ & $\ldots$ & $93 \pm 2.3$ & $93 \pm 4.5$ & $94 \pm 3.5$ \\
\hline
\end{tabular}


respective environments can be estimated from the experimental results.

Among all years and locations in the soil-inoculated plots, it took a minimum of $16 \times 10^{3}$ teliospores/1.2-m row to cause trace amounts of disease in the highly susceptible cultivar Cheyenne. In the same tests, cv. Cheyenne inoculated at $10 \times$ this rate still had only trace amounts or no disease. In one of the nine location-years, trace amounts of disease occurred in cultivar Meridian inoculated at the $16 \times$ $10^{3}$ rate, but Meridian usually was not diseased below the $16 \times 10^{5}$ rate. The 1994 to 1995 Green Canyon plots had the highest overall infection in the positive

Table 2. Percent bunted spikes in winter wheat cultivars Cheyenne (C) and Meridian (M) after inoculating soil with teliospores of Tilletia controversa

\begin{tabular}{|c|c|c|c|c|c|c|c|c|}
\hline \multirow[b]{2}{*}{ Site, year } & \multirow[b]{2}{*}{ Cv. } & \multicolumn{7}{|c|}{ Spores/row } \\
\hline & & $\mathbf{0}$ & $16 \times 10^{2}$ & $16 \times 10^{3}$ & $16 \times 10^{4}$ & $16 \times 10^{5}$ & $16 \times 10^{6}$ & Indicator $^{\mathrm{a}}$ \\
\hline \multicolumn{9}{|c|}{ Green Canyon } \\
\hline \multirow[t]{2}{*}{$1994^{\mathrm{b}}$} & $\mathrm{C}$ & 0 & 0 & $0.6 \pm 1.3$ & 0 & $2.3 \pm 2.6$ & $14.9 \pm 5.2$ & $\ldots$ \\
\hline & $\mathrm{M}$ & 0 & 0 & 0 & 0 & 0 & $1.3 \pm 2.3$ & \\
\hline \multirow[t]{2}{*}{$1995^{b}$} & $\mathrm{C}$ & 0 & 0 & 0 & 0 & $3.4 \pm 2.0$ & $31.7 \pm 17.6$ & 88 \\
\hline & M & 0 & 0 & 0 & 0 & $0.1 \pm 0.1$ & $4.3 \pm 0.8$ & 43 \\
\hline \multirow[t]{2}{*}{$1996^{c}$} & $\mathrm{C}$ & 0 & 0 & $0.3 \pm 0.2$ & $0.3 \pm 0.5$ & $19.1 \pm 5.8$ & $47.2 \pm 15.7$ & 87.2 \\
\hline & M & 0 & 0 & $0.07 \pm 0.1$ & $0.3 \pm 0.6$ & $1.5 \pm 1.3$ & $5.4 \pm 3.1$ & 18.3 \\
\hline \multicolumn{9}{|l|}{ Logan } \\
\hline \multirow[t]{2}{*}{$1994^{\mathrm{b}}$} & $\mathrm{C}$ & 0 & 0 & 0 & 0 & $0.1 \pm 0.2$ & $1.7 \pm 1.5$ & $\ldots$ \\
\hline & $\mathrm{M}$ & 0 & 0 & 0 & 0 & 0 & 0 & 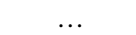 \\
\hline \multirow[t]{2}{*}{$1995^{\mathrm{b}}$} & $\mathrm{C}$ & 0 & 0 & 0 & 0 & $0.2 \pm 0.4$ & $7.6 \pm 5.7$ & 13.4 \\
\hline & $\mathrm{M}$ & 0 & 0 & 0 & 0 & $0.1 \pm 0.1$ & $1.9 \pm 0.5$ & 1.2 \\
\hline \multirow[t]{2}{*}{$1996^{\mathrm{b}}$} & $\mathrm{C}$ & 0 & 0 & 0 & $0.4 \pm 0.2$ & $3.2 \pm 2.2$ & $32.7 \pm 11.5$ & $\mathrm{ND}^{\mathrm{d}}$ \\
\hline & $\mathrm{M}$ & 0 & 0 & 0 & 0 & $0.2 \pm 0.4$ & $2.8 \pm 1.7$ & ND \\
\hline \multicolumn{9}{|l|}{ Kalispell } \\
\hline \multirow[t]{2}{*}{$1994^{\mathrm{b}}$} & $\mathrm{C}$ & 0 & 0 & $0.1 \pm 0.2$ & $0.03 \pm 0.5$ & $1.5 \pm 1.0$ & $12.3 \pm 9.8$ & $\ldots$ \\
\hline & M & 0 & 0 & 0 & 0 & 0 & $0.5 \pm 0.5$ & $\ldots$ \\
\hline \multirow[t]{2}{*}{$1995^{\mathrm{b}}$} & $\mathrm{C}$ & 0 & 0 & 0 & 0 & 0 & $0.8 \pm 0.1$ & 3.6 \\
\hline & $\mathrm{M}$ & 0 & 0 & 0 & 0 & 0 & 0 & 0.1 \\
\hline \multirow[t]{2}{*}{$1996^{\mathrm{b}}$} & $\mathrm{C}$ & 0 & 0 & 0 & 0 & 0 & 0 & 0.2 \\
\hline & $\mathrm{M}$ & 0 & 0 & 0 & 0 & 0 & 0 & 0 \\
\hline
\end{tabular}

${ }^{\text {a }}$ Positive indicator based on soil inoculation of two 3.1-m rows at $10 \times$ the highest test rate. Included only in 1995 and 1996.

${ }^{\mathrm{b}}$ Mean and standard deviation of four replicates of two 1.2-m rows.

$\mathrm{c}$ Mean and standard deviation of three replicates of two 1.2-m rows.

${ }^{\mathrm{d}} \mathrm{ND}=$ rows accidentally plowed.

Table 3. Percent bunted spikes in winter wheat cultivars Cheyenne (C) and Meridian (M) after inoculating seed with teliospores of Tilletia controversa

\begin{tabular}{|c|c|c|c|c|c|c|c|c|}
\hline \multirow[b]{2}{*}{ Site, year } & \multirow[b]{2}{*}{ Cv. } & \multicolumn{7}{|c|}{ Spores/g } \\
\hline & & $\mathbf{0}$ & $2 \times 10^{2}$ & $2 \times 10^{3}$ & $2 \times 10^{4}$ & $2 \times 10^{5}$ & $2 \times 10^{6}$ & Indicator $^{\mathbf{a}}$ \\
\hline \multicolumn{9}{|c|}{ Green Canyon } \\
\hline \multirow[t]{2}{*}{$1994^{\mathrm{b}}$} & $\mathrm{C}$ & 0 & 0 & 0 & 0 & $0.13 \pm 0.3$ & 0 & $\ldots$ \\
\hline & M & 0 & 0 & 0 & 0 & 0 & 0 & $\ldots$ \\
\hline \multirow[t]{2}{*}{$1995^{c}$} & $\mathrm{C}$ & $\ldots$ & $\ldots$ & $\ldots$ & $\ldots$ & $\ldots$ & $\ldots$ & $\ldots$ \\
\hline & M & $\cdots$ & $\ldots$ & $\ldots$ & $\ldots$ & $\ldots$ & $\ldots$ & $\ldots$ \\
\hline \multirow[t]{2}{*}{$1996^{c}$} & $\mathrm{C}$ & ... & $\cdots$ & $\cdots$ & $\ldots$ & $\ldots$ & $\ldots$ & $\ldots$ \\
\hline & M & $\ldots$ & $\ldots$ & $\ldots$ & $\ldots$ & $\ldots$ & $\ldots$ & $\ldots$ \\
\hline \multicolumn{9}{|l|}{ Logan } \\
\hline \multirow[t]{2}{*}{$1994^{\mathrm{b}}$} & $\mathrm{C}$ & 0 & 0 & 0 & 0 & 0 & $0.03 \pm 0.05$ & $\ldots$ \\
\hline & M & 0 & 0 & 0 & 0 & 0 & 0 & $\ldots$ \\
\hline \multirow[t]{2}{*}{$1995^{b}$} & $\mathrm{C}$ & 0 & 0 & 0 & 0 & 0 & $0.4 \pm 0.9$ & 13.4 \\
\hline & M & 0 & 0 & 0 & 0 & 0 & $0.2 \pm 0.2$ & 1.2 \\
\hline \multirow[t]{2}{*}{$1996^{d}$} & $\mathrm{C}$ & 0 & 0 & 0 & 0 & 0 & 0 & $\mathrm{ND}^{\mathrm{e}}$ \\
\hline & M & 0 & 0 & 0 & 0 & 0 & 0 & ND \\
\hline \multicolumn{9}{|l|}{ Kalispell } \\
\hline \multirow[t]{2}{*}{$1994^{\mathrm{b}}$} & $\mathrm{C}$ & 0 & 0 & 0 & 0 & 0 & 0 & $\ldots$ \\
\hline & M & 0 & 0 & 0 & 0 & 0 & 0 & $\ldots$ \\
\hline \multirow[t]{2}{*}{$1995^{\mathrm{b}}$} & $\mathrm{C}$ & 0 & 0 & 0 & 0 & 0 & 0 & 3.6 \\
\hline & $\mathrm{M}$ & 0 & 0 & 0 & 0 & 0 & 0 & 0.1 \\
\hline \multirow{2}{*}{$1996^{\mathrm{b}}$} & $\mathrm{C}$ & 0 & 0 & 0 & 0 & 0 & 0 & 0.2 \\
\hline & $\mathrm{M}$ & 0 & 0 & 0 & 0 & 0 & 0 & 0 \\
\hline
\end{tabular}

a Positive indicator based on soil inoculation of two $3.1-\mathrm{m}$ rows at $10 \times$ the highest test rate. Included only in 1995 and 1996.

${ }^{\mathrm{b}}$ Mean and standard deviation of four replicates of two 1.2-m rows.

${ }^{\mathrm{c}}$ Data excluded because of plot contamination.

${ }^{\mathrm{d}}$ Mean and standard deviation of three replicates of two 1.2-m rows.

${ }^{\mathrm{e}} \mathrm{ND}=$ rows accidentally plowed.

indicator plots, but it took a minimum inoculum level of $16 \times 10^{5}$ spores/row to cause disease in cultivars Cheyenne and Meridian. In all tests, only trace amounts or no disease occurred in cultivars Cheyenne and Meridian inoculated below the $16 \times 10^{5}$ rate. In general, it took about $10 \times$ the inoculation rate of cultivar Cheyenne to produce a similar level of disease in cultivar Meridian.

Among all years and locations in the seed-inoculated plots, a trace of infection occurred in only one replicate of cultivar Cheyenne at the $2 \times 10^{5}$ teliospores/g inoculation rate, but otherwise it took a minimum of $2 \times 10^{6}$ teliospores/g to cause disease, and it occurred only in trace amounts, with the maximum infection of $0.4 \%$. Cultivar Meridian was not diseased by seed inoculation, except for a trace of infection at the highest inoculation rate at Logan in 1995. Most often, seed inoculation produced no disease even at the highest inoculum level.

\section{DISCUSSION}

The results from these experiments clearly demonstrated the interrelationship of soil-surface inoculum levels with the environment to produce different levels of dwarf bunt, and how less inoculum is more effective under more-conducive conditions and more inoculum is required to produce disease under less-conducive conditions. In addition, the experiments showed the effects of disease pressure from inoculum concentration and the environment on the effectiveness of partial resistance. When each of the cultivars was under high disease pressure from both the inoculum and the environment, infection in cultivar Meridian compared to cultivar Cheyenne was much higher than with minimal pressure from either the environment or inoculum concentration. This result demonstrated that the effects of partial resistance are enhanced under limited disease pressure. The partial resistance of cultivar Meridian was adequate to completely prevent dwarf bunt in plots that had limited disease pressure.

Results from the seed-inoculation portion of this study generally confirm a previous study (10), in which statistical methods separated the effect of seed-applied inoculum from natural infection in noninoculated checks. Grey et. al. (10) estimated that there are 20,000 spores/seed at infestation levels of $1 \mathrm{~g}$ of teliospores $/ \mathrm{kg}$ of seed, which is similar to the number of spores contained in a gram that was estimated in this study, given that there are approximately 20 seeds/g. Grey et. al. (10) showed that infection occurred after a minimum inoculation rate of $1 \mathrm{~g}$ of teliospores $/ \mathrm{kg}$ of seed. According to our estimates, this is equivalent to approximately $4 \times 10^{5}$ spores/g of seed. In the current study, a trace of infection $(0.13 \%)$ occurred in one year at one location in the highly 
susceptible cultivar Cheyenne inoculated at $2 \times 10^{5}$ spores/g of seed, but other than this one instance, $2 \times 10^{6}$ spores/g was required to cause dwarf bunt by seed inoculation. The infection level never exceeded $0.4 \%$ in the seed-inoculated test, and most often no infection occurred.

Inducing dwarf bunt with seedborne teliospores has been noted previously $(10,13,23)$, so it was not surprising to confirm those results here. It has been hypothesized that infection from teliospores on seed results from the removal of spores during planting, which then land near the soil surface and cause infection in the normal manner (10). However, it seems unlikely that careful planting by hand would result in significant removal and proper placement of teliospores on the soil surface in sufficient concentration to cause disease.

Experiments with fumigation of grain infested with $T$. controversa teliospores have shown that methyl bromide is a highly effective sporicide for $T$. controversa at high dosage, and particularly under humid conditions (18). In addition, methyl bromide is effective against teliospores of the Karnal bunt pathogen $T$. indica under field conditions (5). It was unknown if methyl bromide also was effective for $T$. controversa teliospores under field conditions; however, the results here demonstrate that fumigation at registered rates killed nearly $100 \%$ of loose teliospores in soil and teliospores contained within intact sori at all depths tested. This high efficacy was essential to the success of these experiments and allowed the introduction of known quantities of inoculum into fields where T. controversa teliospores naturally contaminate the soil. Methyl bromide is degraded or volatilized almost completely within 4 days of application (1), so it is unlikely that the fumigation influenced infection. In an attempt to enhance the activity of methyl bromide, plots were irrigated if necessary at Kalispell and Logan prior to fumigation to produce high soil moisture. Irrigation was not available at the dryland Green Canyon site but, despite low soil moisture there during all years, the fumigation was still very effective, as demonstrated by the efficacy tests and the absence of infection in noninoculated control plots that were protected with the fence.

Some teliospore contamination into at least the edges of the fumigated areas, caused by fall or early winter rains washing surrounding non-fumigated soil into the plots, was expected. Border rows of cultivar Cheyenne that were planted to monitor such contamination showed that it was generally restricted to the outer border rows and did not seem to interfere with the test plots except in two of the three seedinoculated tests at Green Canyon. The soil at Green Canyon is highly infested with teliospores from conducting screening nurseries there for many years, which was evidenced by high disease incidence in nearby non-inoculated plants. The other two instances, where apparent contamination caused one replicate to be eliminated at both Green Canyon and Logan in 1996, seemed to be caused by the failure of methyl bromide rather than inoculum movement from outside the fumigated areas, because the contamination occurred in an isolated spot. In addition, at Green Canyon, the test plot that appeared to be influenced was surrounded with the 1.2-m high plywood fence, which eliminated washing into the plot.

The fences used to separate teliospore concentrations for the soil-inoculation experiments appeared to effectively contain the teliospores within test plots. This technique, when performed in conjunction with additional safeguards, could be used to test the disease-conducive nature of areas where the environmental suitability for dwarf bunt is questionable.

Dwarf bunt was not induced at soil inoculum levels below $16 \times 10^{3}$ teliospores/1.2-m row, but we cannot conclude that infection is impossible below this level. The disease likely could have been detected at inoculum levels lower than those found in these experiments if the plots were sufficiently large. Also, it is possible that dwarf bunt could have been detected at lower inoculum levels in environments that are even more conducive than those encountered during the course of this study. Under ideal environmental conditions that rarely occur in highly inoculated experimental screening nurseries, it is not uncommon for cv. Cheyenne to have more than $95 \%$ infected spikes and cv. Meridian to have up to $60 \%$ infected spikes (B. J. Goates, unpublished). Regardless, it appears that the inoculum level required to induce dwarf bunt under field conditions is fairly high.

Winter wheat plants are more susceptible to dwarf bunt when planted at the shallow seeding depths that were used in this study, as compared with deeper seeding $(12,16,22)$. Also, plants are more susceptible at early developmental stages when they become dormant as they go into winter (12). In commercial farming operations, plants typically are well beyond the most susceptible 1- to 3-leaf stage during winter. If the plants in these experiments were planted at normal commercial seeding depths, and/or were beyond the most susceptible stage of growth that was tested here, it is likely that the disease reactions would have been less severe.

Theoretically, only a single teliospore is necessary to cause infection, but the chance of this occurring seems extremely remote. The results from these experiments aid the understanding of what lies between the theoretical single spore and actual number of teliospores required to cause detectable levels of disease in conducive environments. The experiments also dem- onstrate the inoculum concentration required to cause slight to damaging levels of disease in highly conducive environments when plants are managed to be in a susceptible state. This information should aid assessment of the risk of introducing dwarf bunt into new areas by way of international grain shipments destined for milling.

\section{ACKNOWLEDGMENTS}

We thank R. Stougarrd and T. Keener of Montana State University, and D. Hole of Utah State University, for assistance with fields and plot maintenance

\section{LITERATURE CITED}

1. Anderson, T. A., Rice, P. J., Cink, J. H., and Coats, J. R. 1996. Fate of methyl bromide in fumigated soils. Pages 42-52 in: Fumigants: Environmental Fate, Exposure, and Analysis, ACS Symposium Series 652. J. N. Seiber et al., eds. American Chemical Society, Washington, DC.

2. Datnoff, L. E., Royer, M. H., and Bonde, M. R. 1988. A quantitative method for estimation of teliospores of Tilletia indica in soil. Plant Dis. 72:209-212.

3. Fernandez, J. A., Durán, R., and Schafer, J. F. 1978. Histological aspects of dwarf bunt resistance in wheat. Phytopathology 68:14171421.

4. Food and Agriculture Organization of the United Nations. International Standards for Phytosanitary Measures. Part 1-Import Regulations: Guidelines for Pest Risk Analysis. Publ. No. 2, February 1996.

5. Fuentes-Dávila, G., and Lawn, D. A. 1992. Effects of methyl bromide and dazomet on germination of Tilletia indica teliospores in field soil. Trop. Pest Manage. 38:323-324.

6. Goates, B. J. 1992. Control of dwarf bunt of wheat by seed treatment with Dividend 3FS. Fungic. Nematic. Tests 47:264.

7. Goates, B. J. 1994. Resistance to dwarf bunt among winter wheat cultivars. Phytopathology $84: 1116$.

8. Goates, B. J. 1996. Common bunt and dwarf bunt. Pages 12-25 in: Bunt and Smut Diseases of Wheat: Concepts and Methods of Disease Management. R. D. Wilcoxson and E. E. Saari, eds. CIMMYT, Mexico City.

9. Goates, B. J. 1998. Host resistance to dwarf bunt of wheat. Pages 317-326 in: Bunts and Smuts of Wheat: An International Symposium. V. S. Malik and D. E. Mathre, eds. North American Plant Protection Organization, Ottawa, Canada.

10. Grey, W. E., Mathre, D. E., Hoffmann, J. A., Powelson, R. L., and Fernandez, J. A. 1986. Importance of seedborne Tilletia controversa for infection of winter wheat and its relationship to international commerce. Plant Dis. 70:122-125.

11. Hoffmann, J. A. 1982. Bunt of Wheat. Plant Dis. 66:979-986.

12. Hoffmann, J. A., and Purdy, L. H. 1967. Effect of stage of development of winter wheat on infection by Tilletia controversa. Phytopathology 57:410-413.

13. Holton, C. S., Bamberg, R. H., and Woodward, R. W. 1949. Progress in the study of dwarf bunt on winter wheat in the Pacific Northwest. Phytopathology 39:986-1000.

14. Keener, T. W., Stougaard, R. N., and Mathre, D. E. 1995. Effect of winter wheat cultivar and difenoconazole seed treatment on dwarf bunt. Plant Dis. 79:601-604.

15. Mathre, D. E. 1996. Dwarf Bunt: Politics, Identification, and Biology. Annu. Rev. Phytopathol. 34:67-85.

16. Meiners, J. P., Kendrick, E. L., and Holton, C. 
S. 1956. Depth of seeding as a factor in the incidence of dwarf bunt and its possible relationship to spore germination on or near the soil surface. Plant Dis. Rep. 40:242-243.

17. Purdy. L. H., Hoffmann, J. A., Meiners, J. P., and Stewart, V. R. 1963. Time of year of infection of winter wheat by the dwarf bunt fungus. Phytopathology 53:1419-1421.

18. Sitton, J., Wiese, M., Goates, B., Forster, R. Line, R., Mathre, D., Peterson, C., Smiley, R., and Waldher, J. 1995. Dwarf bunt of wheat in the Northwest. Pacific Northwest Extension Publications, Pullman, WA.
19. Sitton, J. W., Line, R. F., Waldher, J. T., and Goates, B. J. 1993. Difenoconazole seed treatment for control of dwarf bunt of winter wheat. Plant Dis. 77:1148-1151.

20. Smilanick, J. L., Hartsell, P. L., Denis-Arrue, R., Henson, D. J., McKinney, J. D., Tebbets, J. C., and Goates, B. J. 1992. Survival of common and dwarf bunt teliospores and intact sori after fumigation of high and low moisture content winter wheat. Plant Dis. 76:293-296.

21. Trione, E. J. 1982. Dwarf bunt of wheat and its importance in international wheat trade. Plant Dis. 66:1083-1088.
22. Tyler, L. J., and Jensen, N. F. 1958. Some factors that influence development of dwarf bun in winter wheat. Phytopathology 48:565-571.

23. Wagner, F. 1949. Beobachtungen uber Zwersteinbrand. Nachrichtenvlatt der Biologischen Zentralanstalt Braunschweig 1:39-40.

24. Young, P. A. 1935. A new variety of Tilletia tritici in Montana. Phytopathology 73:14231428 .

25. Zhang, Z., Zhang, C. R., and Wang, Z. Z. 1995. Plant quarantine significance of wheat dwarf bunt in China. OEPP/EPPO Bull. 25:665-671. 